\title{
Risk factors for early and late recurrent ischemic strokes
}

\author{
Hassan Mohammed Elnady ${ }^{*}$, Gharib Fawi Mohammed, Hazem Kamal Elhewag, Mohamed Khodery Mohamed and \\ Ahmed Borai
}

\begin{abstract}
Background: Nationally, information regarding risk factors for early and late recurrence of ischemic stroke is limited. Objectives: The aim of this study was to identify the risk factors for early and late recurrent ischemic stroke.

Patients and methods: We prospectively compared data from 58 patients with early (within 1 year after the index stroke) recurrent ischemic stroke with 64 patients with late (1 year or more after the index stroke) recurrent ischemic stroke. Patients in the study were admitted to the Department of Neurology and Psychological Medicine, Sohag University Hospital, in the period between April 2017 and August 2017. The etiology of recurrent stroke was determined according to the TOAST classification. The presence of vascular risk factors was registered and compared in both groups.

Results: Systolic blood pressure was significantly higher among those with late recurrence compared to those with early recurrence $(p=0.026)$. Patients with early recurrent ischemic stroke were more likely to be aphasic $(p=0.047)$. Regarding the TOAST classification, small vessel disease and undetermined etiology were significantly higher among patients with late recurrence, while cardioembolism and large artery atherosclerosis were significantly higher among those with early recurrence $(p=0.008)$.
\end{abstract}

Conclusion: Patients with large artery atherosclerosis and cardioembolism are at increased risk of early recurrence and warrant special efforts for secondary prevention.

Keywords: Ischemic stroke, Recurrent stroke, Cardiovascular risk factors, Stroke etiology

\section{Introduction}

Cerebrovascular stroke is the 5th cause of death in the First World countries [1]. Up to $25 \%$ of the total number of strokes occurring annually in the USA are recurrent strokes [2]. Nevertheless, following advancements in primary and secondary preventive care, the incidence of recurrent stroke is high. For Western countries, the first 5year cumulative incidence of stroke recurrence ranges from 16 to $30 \%$ [3-5]. About 50\% of patients surviving an ischemic stroke or TIA have an increased risk of recurrent stroke within a few days or weeks of the initial insult, with the highest risk during the first week [6]. As the risk of

\footnotetext{
* Correspondence: elnadyhassan1974@hotmail.com; hass_elnady@yahoo.com Department of Neurology and Psychological Medicine, Faculty of Medicine, Sohag University, Sohag, Egypt
}

\section{Springer Open}

recurrent stroke is most prominent in the first few months after stroke, it is important to identify factors associated with early recurrence in order to establish effective treatments for secondary stroke prevention [7]. Standard stroke prevention practices are determining the etiology and treating patients using pharmacological agents (e.g., antiplatelets and anticoagulants); moreover, carotid endarterectomy and stenting procedures (non-pharmacological measures) are used for occlusive vascular lesions [8]. The aim of this study was to identify the risk factors for early and late recurrent ischemic stroke.

\section{Patients and methods}

This is a prospective cross-sectional comparative study, comparing patients with early recurrent ischemic stroke (c) The Author(s). 2020 Open Access This article is licensed under a Creative Commons Attribution 4.0 International License, which permits use, sharing, adaptation, distribution and reproduction in any medium or format, as long as you give appropriate credit to the original author(s) and the source, provide a link to the Creative Commons licence, and indicate if changes were made. The images or other third party material in this article are included in the article's Creative Commons licence, unless indicated otherwise in a credit line to the material. If material is not included in the article's Creative Commons licence and your intended use is not permitted by statutory regulation or exceeds the permitted use, you will need to obtain permission directly from the copyright holder. To view a copy of this licence, visit http://creativecommons.org/licenses/by/4.0/. 
and those with late recurrent ischemic stroke. We prospectively compared data from consecutive patients with recurrent ischemic stroke. Patients were divided into 2 groups according to the time of the recurrence. Group A includes 58 patients with stroke recurrence within 1 year after the index ischemic stroke. Group B includes 64 patients with stroke recurrence 1 year after the index ischemic stroke or later. Selecting 1 year as a cut point was according to the recent trend in the design of stroke studies [9]. Patients in the study were admitted to the Department of Neurology and Psychological Medicine, Sohag University Hospital, in the period between April 2017 and August 2017. The study was approved by the Medical Research Ethical Committee of the Sohag Faculty of Medicine. Consents were obtained from participants. Ischemic stroke was defined as an episode of neurological dysfunction caused by focal cerebral, spinal, or retinal infarction [10]. Recurrent stroke was defined as a new neurologic deficit meeting the standard definition of a stroke, which occurred after a period of neurological improvement or stability lasting at least $24 \mathrm{~h}$ [11].

\section{Inclusion criteria}

The inclusion criteria were all patients with recurrent ischemic stroke admitted to the neurology department from April 2017 to August 2017 and age above 18 years old.

\section{Exclusion criteria}

Patients were excluded from the study if they had a cerebral hemorrhage, first in life ischemic stroke, or TIA.

All subjects had complete history and comprehensive medical and neurological evaluation. Patients with smoking history past or present had been identified as smokers. Hypertension was described as self-reporting of hypertension and/or systolic blood pressure greater than or equal to $140 \mathrm{mmHg}$ and/or diastolic blood pressure greater than or equal to $90 \mathrm{mmHg}$. Diabetes had been described as self-reporting and/or fasting glucose levels greater than or equal to $126 \mathrm{mg} / \mathrm{dL}$ for diabetes treatment. Hypercholesterolemia had been identified as cholesterol in excess of $200 \mathrm{mg} / \mathrm{dL}$ or in the presence of a particular treatment. Hypertriglyceridemia was described as more than $200 \mathrm{mg} / \mathrm{dL}$ of triglyceride. Admission stroke severity was assessed by the Scandinavian Stroke Scale (SSS) and the National Institute of Health Stroke Scale (NIHSS). Standard approaches had been used to obtain biochemical parameters and cell counts.

CT brain (GE light speed 8 slice model 2009 CT machine, USA), transthoracic echocardiogram (GE Logique P5 ultrasound machine), and carotid Doppler (GE Logique P9 ultrasound machine, Japan) were also done for all patients. The extracranial carotid arteries were scanned bilaterally according to standard methodology. According to the findings, the patients were divided into four groups: first group, patients with normal carotid Doppler study; second group, patients with diffuse atherosclerotic changes; third group, patients with atheromatous plague with no significant stenosis; and fourth group, patients with atheromatous plaque with significant stenosis.

The etiology of ischemic stroke was determined according to the criteria developed for the Trial of Org 10172 in Acute Stroke Treatment (TOAST). The five classes of IS were identified by etiology, that is, (i) large artery atherosclerosis, (ii) cardioembolism, (iii) small artery occlusion, (iv) other determined etiologies, and (v) unknown etiologies [12].

\section{Statistical data analysis}

Statistical analysis of our data was done by Statistical Package for the Social Sciences (SPSS version 20) for Windows. Continuous data were expressed as mean \pm standard deviation (SD), with categorical data expressed as numbers and percentages. Student's $t$ test for continuous data and chi-square test for categorical data carried out comparisons of differences between the two groups. The Fisher exact test was used in non-parametric data instead of the Pearson chi-square test. The statistically significant $p$ values equal to or less than 0.05 are considered.

\section{Results}

Four hundred thirty-eight patients with cerebrovascular stroke admitted to our department between April 2017 and August 2017 were screened for inclusion criteria. Sixty-five patients were excluded because of the diagnosis of cerebral hemorrhage; 234 were excluded due to the diagnosis of first-ever ischemic stroke. Only 139 patients were diagnosed as recurrent ischemic stroke after 17 patients were excluded due to missed data, and therefore, only 122 patients were finally included in the statistical analysis. Among these patients, 58 patients with early recurrent ischemic stroke were categorized as group A and 64 patients with late recurrence were categorized as group B. Figure 1 shows the flow chart of the patients admitted during the study.

The baseline characteristics of the patients are shown in Table 1 . The mean $( \pm \mathrm{SD})$ time till admission in hours was $15.47 \pm 13.26$. Weakness was the most frequent symptom on admission (50.8\%), followed by dysarthria (17.2\%), aphasia (15.6\%), seizures (6.6\%), and ataxia (3.3\%).

Table 2 presents the demographic data and risk factors in patients with early and late recurrent ischemic stroke. None of these parameters was significantly different in both groups.

Table 3 revealed the clinical, laboratory, and radiological data in both groups, on admission. Systolic blood 


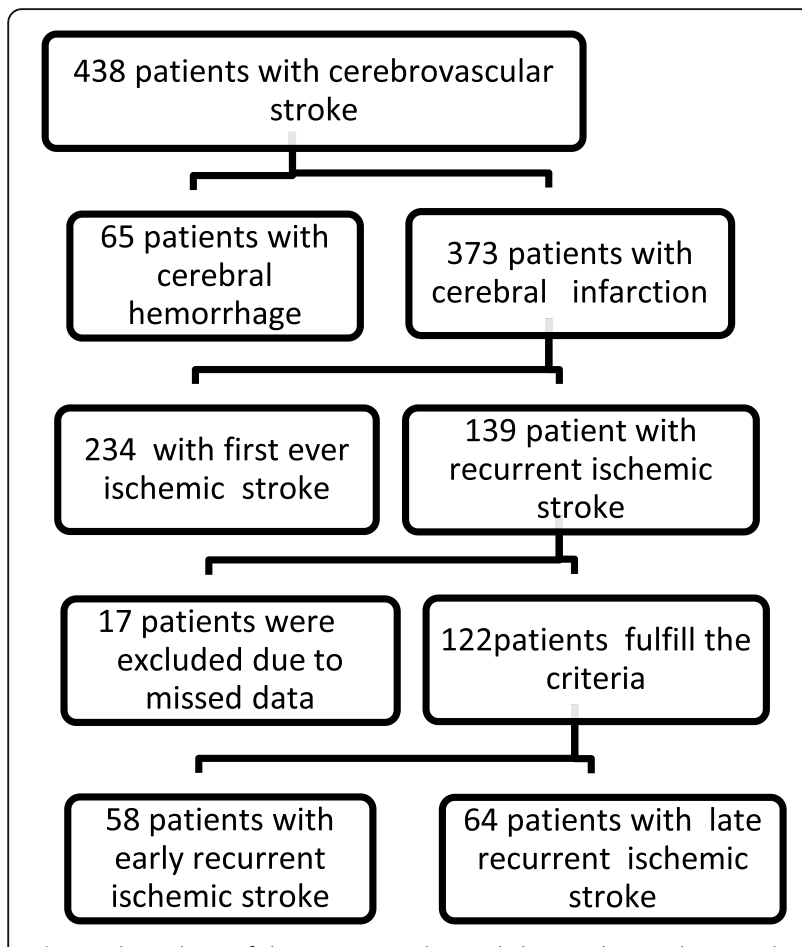

Fig. 1 Flow chart of the patients admitted during the study period

Table 1 Baseline characteristics of the patients included in the analysis

\begin{tabular}{ll}
\hline Age, mean \pm SD (years) & $65.4 \pm 10.1$ \\
\hline Gender & \\
Male, $n(\%)$ & $66(54.1 \%)$ \\
Female, $n(\%)$ & $56(45.9 \%)$ \\
Hypertension, $n$ (\%) & $79(64.8 \%)$ \\
DM, $n$ (\%) & $42(34.4 \%)$ \\
Smoking & \\
Ex-smoker, $n$ (\%) & $19(15.6 \%)$ \\
Current smoker, $n$ (\%) & $30(24.6 \%)$ \\
Cardiac diseases & \\
IHD, $n$ (\%) & $35(28.7 \%)$ \\
AF, $n$ (\%) & $13(10.7 \%)$ \\
Arrhythmias rather than AF $n$ (\%) & $3(2.5 \%)$ \\
Old Ml, $n$ (\%) & $16(13.1 \%)$ \\
Parents' consanguinity, $n$ (\%) & $20(16.4 \%)$ \\
Family history of similar conditions, $n(\%)$ & $11(9 \%)$ \\
NIHSS, mean \pm SD & $8.25 \pm 4.81$ \\
Etiology of recurrent stroke (TOAST) & \\
Large artery atherosclerosis, $n(\%)$ & $18(14.8)$ \\
Cardioembolic, $n$ (\%) & $29(23.8)$ \\
Small vessel disease, $n(\%)$ & $57(46.7)$ \\
Undetermined etiology, $n(\%)$ & $18(14.8)$ \\
\hline
\end{tabular}

$D M$ diabetes mellitus, $I H D$ ischemic heart disease, $A F$ atrial fibrillation, $M I$ myocardial infarction
Table 2 Demographic data and risk factors in both groups

\begin{tabular}{|c|c|c|c|}
\hline & $\begin{array}{l}\text { Group A, early } \\
\text { recurrent IS, } n=58\end{array}$ & $\begin{array}{l}\text { Group B, late } \\
\text { recurrent IS, } n=64\end{array}$ & $\begin{array}{l}p \\
\text { value }\end{array}$ \\
\hline $\begin{array}{l}\text { Age, mean } \pm S D \\
\text { (years) }\end{array}$ & $64.7 \pm 10.7$ & $66.0 \pm 9.6$ & 0.489 \\
\hline \multicolumn{4}{|l|}{ Sex } \\
\hline Male, $n(\%)$ & $30(51.7 \%)$ & $36(56.3 \%)$ & \multirow[t]{2}{*}{0.616} \\
\hline Female, $n(\%)$ & $28(48.3 \%)$ & $28(43.8 \%)$ & \\
\hline Hypertension, n (\%) & $34(58.6 \%)$ & $45(70.3 \%)$ & 0.177 \\
\hline $\mathrm{DM}, n(\%)$ & 22 (37.9\%) & $20(31.2 \%)$ & 0.438 \\
\hline \multicolumn{4}{|l|}{ Smoking } \\
\hline Ex-smoker, $n(\%)$ & $9(15.5 \%)$ & $10(15.6 \%)$ & \multirow[t]{2}{*}{0.858} \\
\hline $\begin{array}{l}\text { Current smoker, } n \\
(\%)\end{array}$ & $13(22.4 \%)$ & $17(26.6 \%)$ & \\
\hline \multicolumn{4}{|l|}{ Cardiac disease } \\
\hline $\mathrm{HD}_{1}, n(\%)$ & $16(27.6 \%)$ & 19 (29.7\%) & 0.798 \\
\hline $\begin{array}{l}\text { Arrhythmia rather } \\
\text { than } A F, n(\%)\end{array}$ & $2(3.4 \%)$ & $1(1.6 \%)$ & 0.604 \\
\hline $\mathrm{AF}, n(\%)$ & $8(13.8 \%)$ & $5(7.8 \%)$ & 0.285 \\
\hline Old MI, n (\%) & $6(10.3 \%)$ & $10(15.6 \%)$ & 0.388 \\
\hline \multicolumn{4}{|l|}{ Antiplatelet therapy } \\
\hline Compliant, $n$ (\%) & $11(19 \%)$ & $11(17.2 \%)$ & \multirow[t]{2}{*}{0.799} \\
\hline $\begin{array}{l}\text { Non-compliant, } n \\
(\%)\end{array}$ & $47(81 \%)$ & $53(82.8 \%)$ & \\
\hline Similar conditions, $n$ & $5(8.6 \%)$ & $6(9.4 \%)$ & 0.884 \\
\hline
\end{tabular}

(\%)

$D M$ diabetes mellitus, $I H D$ ischemic heart disease, $A F$ atrial fibrillation, $M I$ myocardial infarction

pressure was significantly higher among those with late recurrence compared to those with early recurrence ( $p=$ 0.026). Patients with early recurrent ischemic stroke were more likely to be aphasic $(p=0.047)$. Regarding the TOAST classification, small vessel disease and undetermined etiology were significantly higher among patients with late recurrence, while cardioembolism and large artery atherosclerosis were significantly higher among those with early recurrence $(p=0.008)$. Regarding carotid Doppler findings, diffuse atherosclerotic changes were significantly higher among patients with early recurrent ischemic stroke $(p=0.030)$. The echocardiographic finding that has a significant difference between patients with early and late recurrence was valvular heart disease, which was much higher among cases with early recurrence $(p=0.019)$.

The data were further analyzed by multivariate logistic regression (Table 4). The dependent variable was early recurrence, and the independent variables were SBP and the presence of valvular heart disease and large artery atherosclerosis. This analysis revealed that the presence of large artery atherosclerosis was independently associated with increased risk of early recurrence $(p=0.032)$. 
Table 3 Clinical, laboratory, and radiological data in both groups, on admission

\begin{tabular}{|c|c|c|c|}
\hline & Group A, early recurrent IS, $n=58$ & Group B, late recurrent IS, $n=64$ & $p$ value \\
\hline \multicolumn{4}{|l|}{ Blood pressure } \\
\hline $\mathrm{SBP}(\mathrm{mmHg})$, mean $\pm \mathrm{SD}$ & $133.5 \pm 22.3$ & $146.1 \pm 23.0$ & 0.026 \\
\hline $\mathrm{DBP}(\mathrm{mmHg})$, mean $\pm \mathrm{SD}$ & $85.9 \pm 13.7$ & $88.6 \pm 10.4$ & 0.291 \\
\hline Temperature, mean \pm SD & $37.2 \pm 0.3$ & $37.1 \pm 0.2$ & 0.121 \\
\hline Respiratory rate, mean \pm SD & $17.2 \pm 1.4$ & $17.0 \pm 1.2$ & 0.502 \\
\hline Pulse, mean \pm SD & $81.1 \pm 12.4$ & $79.1 \pm 11.5$ & 0.433 \\
\hline Seizures, $n(\%)$ & $5(62.5 \%)$ & $3(37.5 \%)$ & 0.407 \\
\hline Aphasia, $n$ (\%) & $13(68.4 \%)$ & $6(31.6 \%)$ & 0.047 \\
\hline Dysarthria, $n$ (\%) & $11(52.4 \%)$ & $10(47.6 \%)$ & 0.625 \\
\hline Motor weakness, n (\%) & $27(43.5 \%)$ & $35(56.5 \%)$ & 0.369 \\
\hline Ataxia, $n(\%)$ & $2(50 \%)$ & $2(50 \%)$ & 0.920 \\
\hline $\mathrm{GCS}$, mean $\pm \mathrm{SD}$ & $13.84 \pm 1.86$ & $13.93 \pm 1.87$ & 0.813 \\
\hline $\mathrm{NIHSS}$, mean $\pm \mathrm{SD}$ & $8.80 \pm 5.03$ & $7.77 \pm 4.60$ & 0.277 \\
\hline$S S S$, mean $\pm S D$ & $47.80 \pm 9.19$ & $48.57 \pm 7.91$ & 0.643 \\
\hline \multicolumn{4}{|l|}{ Etiology of IS (TOAST) } \\
\hline Large artery atherosclerosis, $n(\%)$ & $10(17.2 \%)$ & $8(12.5 \%)$ & 0.008 \\
\hline Cardioembolic, $n$ (\%) & $21(36.2 \%)$ & $8(12.5 \%)$ & \\
\hline Small vessel, $n(\%)$ & $20(34.5 \%)$ & $37(57.8 \%)$ & \\
\hline Undetermined (\%) & $7(12.1 \%)$ & $11(17.2 \%)$ & \\
\hline Blood sugar, mean \pm SD & $181.81 \pm 37.28$ & $194.53 \pm 49.94$ & 0.119 \\
\hline Creatinine, mean \pm SD & $1.03 \pm 0.51$ & $1.24 \pm 0.82$ & 0.129 \\
\hline $\mathrm{RBCs}$, mean $\pm \mathrm{SD}$ & $4.71 \pm 0.63$ & $4.68 \pm 0.70$ & 0.300 \\
\hline $\mathrm{HGB}$, mean $\pm \mathrm{SD}$ & $12.34 \pm 2.22$ & $12.68 \pm 1.70$ & 0.381 \\
\hline WBCs, mean \pm SD & $9.35 \pm 3.7$ & $8.94 \pm 4.9$ & 0.175 \\
\hline Platelets, mean \pm SD & $203.86 \pm 60.48$ & $205.98 \pm 65.48$ & 0.777 \\
\hline $\mathrm{ESR}$, mean $\pm \mathrm{SD}$ & $32.77 \pm 20.81$ & $36.64 \pm 26.62$ & 0.753 \\
\hline Cholesterol, mean \pm SD & $160.14 \pm 51.56$ & $173.92 \pm 42.47$ & 0.146 \\
\hline Triglyceride, mean \pm SD & $117.00 \pm 79.49$ & $163.16 \pm 200.65$ & 0.138 \\
\hline Uric acid, mean \pm SD & $5.60 \pm 1.49$ & $5.68 \pm 1.87$ & 0.820 \\
\hline \multicolumn{4}{|l|}{ Carotid Doppler } \\
\hline Diffuse atherosclerotic changes, $n(\%)$ & $21(36.2 \%)$ & $12(18.8 \%)$ & 0.030 \\
\hline Atheromatous plaque with non-significant stenosis, $n(\%)$ & $9(15.5 \%)$ & $17(26.6 \%)$ & 0.137 \\
\hline Atheromatous plaque with significant stenosis, $n$ (\%) & $9(15.5 \%)$ & $7(10.9 \%)$ & 0.454 \\
\hline \multicolumn{4}{|l|}{ Echocardiography } \\
\hline Valvular heart disease & $16(27.6 \%)$ & $7(10.9 \%)$ & 0.019 \\
\hline $\mathrm{LVH}$ & $18(31 \%)$ & $30(46.9 \%)$ & 0.074 \\
\hline
\end{tabular}

RBS random blood sugar, $R B C s$ red blood corpuscles, $H G B$ hemoglobin, $A L T$ alanine transaminase, $A S T$ aspartate transaminase, MPV mean platelet volume, ESR erythrocyte sedimentation rate, WBCs white blood cells, Bil.T bilirubin total, To.Prot total protein, $L V H$ left ventricular hypertrophy

\section{Discussion}

To the best of our knowledge, this is the first prospective study comparing early and late recurrent ischemic stroke in Egypt. We found that large artery atherosclerosis and cardioembolism are associated with early recurrent ischemic stroke while small vessel disease is associated with late recurrent ischemic stroke. We also found that systolic blood pressure was significantly higher among patients with late recurrence.

Our 1-year selection as a separation point for patients with early and late recurrent ischemic stroke corresponds to the recent trend in the design of stroke studies [9]. Amarenco and colleagues reported that the risk of recurrent stroke within and after the first week and after 
Table 4 Multivariate logistic regression analysis of the possible risk factors for early recurrence

\begin{tabular}{llll}
\hline Item & Odds ratio & Cl of odds & $p$ value \\
\hline Systolic blood pressure & 0.982 & $0.963-1.001$ & 0.063 \\
Large artery atherosclerosis & 2.435 & $1.566-10.477$ & 0.032 \\
Valvular heart disease & 1.694 & $0.568-5.051$ & 0.345 \\
\hline
\end{tabular}

1 month, 3 months, and 1 year was less than half that expected from historical cohorts. The 1-year risk still poses a short-term risk for the prevention of strokes for a lifetime [9]. The early and late categorization of our subjects combined with the etiologic classification (TOAST criteria) has enabled us to know which subtype of stroke is associated with early or late recurrence and to unmask the previous controversy as regards the causes of recurrent stroke.

The ranking of the etiologic groups demonstrates different data in the studies that were conducted by different authors [8]. In a previous study that evaluated 889 patients with recurrent ischemic stroke, small vessel disease was the most common causative factor [13]. In another study, cardioembolic strokes were the most common etiological factor followed by strokes with an undetermined etiology [14]. The strokes due to undetermined etiologies and cardioembolic strokes were the most common causes in the study that Murat Sumer and Erturk [15] conducted in 2002. In the study conducted by Kolominsky-Rabas and colleagues [3] in Europe, cardioembolic strokes positioned first and strokes due to large vessel atherosclerosis positioned second in the disease group.

We found that large artery atherosclerosis was statistically higher among patients with early recurrence. This is in accord with a study by Lovett and colleagues who reported that patients with large artery atherosclerotic disease have a high early risk of recurrent ischemic stroke compared with other etiologic subtypes, whereas patients with ischemic strokes due to small vessel disease have the lowest risk of early recurrence [11].

Also, in agreement with our study, Kocaman and colleagues reported that large artery atherosclerosis is the most common etiology for recurrent ischemic stroke [8].

Atherosclerosis in major intracranial arteries prompts changes running from minor thickening of the arterial wall to a significant hemodynamic stenosis of the arterial lumen and is a standout among the most common causes of stroke worldwide [16].

A prior investigation revealed that patients with minor stroke who have more than $70 \%$ stenosis of the internal carotid artery (ICA) had a higher rate of recurrent ischemic stroke, which indicates that severe symptomatic extra- or intracranial arterial disease was independently associated with 7-day and 90-day stroke recurrence in minor stroke patients [17].

In their hypothesis, Hankey and colleagues reported that atheroma (the common cause of stroke) is an acute on top of chronic disease, causing recurrent attacks of thromboembolism before settling down as the endothelium of the ulcerated plaque heals [18]. Moreover, animal experimental studies demonstrated that a prior thromboembolic event enhanced the vulnerability of the brain to a subsequent ischemic insult $[19,20]$. In line with these data, diffuse atherosclerotic changes in the form of increased intima-media thickness were significantly higher among our patients with early recurrence.

In our study, patients with early recurrent stroke were more likely to have cardioembolic stroke; this was in line with Petty and colleagues, who reported that cardioembolic strokes were the most common cause of recurrent ischemic stroke followed by strokes with an undetermined etiology [14].

Also in line with our findings, the strokes due to undetermined etiologies and cardioembolic strokes were the most common causes with similar frequencies in the study of Murat Sumer and Erturk [15].

Moreover, in the study conducted by KolominskyRabas and colleagues in Europe, cardioembolic strokes ranked first and strokes due to large vessel atherosclerosis ranked second in the disease group [3].

Among our population, the prevalence of small vessel disease among patients with late recurrent ischemic stroke was significantly higher than those with early recurrent ischemic stroke. In agreement with our findings, Leoo and colleagues reported that, according to the TOAST subtypes of the ischemic stroke group, "small vessel disease" was the most common cause of RIS; they also reported that the majority of the patients $(75 \%)$ had their previous stroke $>12$ months before the admission [13].

In agreement with Leoo and colleagues [13], hypertension was the most frequent vascular risk factor among our population $(65 \%)$.

It was stated in the literature that stroke recurrence increases fourfold in the presence of hypertension, and approximately $60-75 \%$ of strokes occur in the presence of hypertension [21]. As shown in a metaanalysis of 7 randomized controlled studies, antihypertensive drugs reduce stroke recurrence after stroke or TIA [22].

Various meta-analyses showed that efficient antihypertensive treatment reduces the rate of recurrence of strokes by $30-40 \%$ [22-24]. It was also reported in another study that an adequate antihypertensive treatment reduces the rate of stroke recurrence by $50 \%$ [25].

The researchers stated in another study that hypertension is a significant modifiable risk factor in their patient population to prevent stroke recurrence [8]. 
Although we did not find a significant difference between patients with early and late recurrence as regards the prevalence of hypertension, systolic blood pressure was significantly higher among patients with late recurrent ischemic stroke. This may mean that uncontrolled hypertension played a key role as a risk factor for small vessel disease. In line with our findings, in the study, Laloux and colleagues found that the proportion of patients with recurrent stroke who received inadequate antihypertensive medication was 39\% [26].

As regards the clinical presentation, we have found that aphasia was significantly more common in patients with early recurrent stroke. In line with our results, researchers in the Oxfordshire Community Stroke Project found that patients with higher cortical dysfunction (e.g., aphasia, visuospatial disorder) were significantly more likely to have an early recurrent stroke due to a partial anterior circulation infarction [27].

A limitation of our study is that the index stroke was not restricted to the first-ever ischemic stroke; however, with reference to a previous study, recurrent stroke subtypes were the same as the index stroke in a large proportion of patients [28]. Dependence on the TOAST classification, in addition to the small size of the sample, made us deal with small vessel disease as a single category. Indeed, small vessel disease is a broad term covering lacunar brain infarcts, white matter hyperintensities, cerebral microbleeds, and atrophy attributed to the vascular origin.

Based on our findings, patients with LAA and CE are at increased risk of early recurrence and warrant special efforts for secondary prevention. Future research should aim at establishing clinical, serological, and imaging biomarkers that can identify high-risk patients. In addition, there is an urgent need to develop novel therapies to lower the risk of stroke in these high-risk patients.

\section{Acknowledgements}

Not applicable

\section{Authors' contributions}

GF participated in the design of the study and supervised the findings of this work. HE conceived the study and participated in its design and coordination. $A B$ analyzed the data and involved in the study design. HE and MK wrote the paper, drafted the manuscript, and designed the tables. MK and $\mathrm{HE}$ were involved in the data acquisition and analysis. HK revised the manuscript. All authors discussed the results and commented on the manuscript. All authors read and approved the final manuscript.

\section{Funding}

The authors did not receive any grants, equipment, nor drugs for this paper.

\section{Availability of data and materials}

The data set of this work is available and uploaded with this article.

\section{Ethics approval and consent to participate}

The study was approved by the local Ethical Committee of Sohag Faculty of Medicine, Sohag University, on April 9, 2017. Informed written (when available) consent was obtained from all patients for participation and publication of this study.
Consent for publication

Not applicable.

\section{Competing interests}

The authors declare that they have no competing interests.

Received: 9 August 2019 Accepted: 5 June 2020

Published online: 17 June 2020

\section{References}

1. Mozaffarian D, et al. Heart disease and stroke Statistics-2016 update: a report from the American Heart Association. Circulation. 2016;133(4):e38-360.

2. Oza R, Rundell K, Garcellano M. Recurrent ischemic stroke: strategies for prevention. Am Fam Physician. 2017;96(7):436-40.

3. Kolominsky-Rabas PL, et al. Epidemiology of ischemic stroke subtypes according to TOAST criteria: incidence, recurrence, and long-term survival in ischemic stroke subtypes: a population-based study. Stroke. 2001;32(12): 2735-40.

4. Mohan KM, et al. Frequency and predictors for the risk of stroke recurrence up to 10 years after stroke: the South London stroke register. J Neurol Neurosurg Psychiatry. 2009;80(9):1012-8.

5. Mohan KM, et al. Risk and cumulative risk of stroke recurrence: a systematic review and meta-analysis. Stroke. 2011;42(5):1489-94.

6. Arsava EM, et al. Prediction of early recurrence after acute ischemic stroke. JAMA Neurol. 2016;73(4):396-401.

7. Kang DW, et al. Inflammatory and hemostatic biomarkers associated with early recurrent ischemic lesions in acute ischemic stroke. Stroke. 2009;40(5): 1653-8.

8. Kocaman $\mathrm{G}$, et al. Recurrent ischemic stroke characteristics and assessment of sufficiency of secondary stroke prevention. Noro Psikiyatr Ars. 2015;52(2): 139-44.

9. Amarenco $\mathrm{P}$, et al. One-year risk of stroke after transient ischemic attack or minor stroke. N Engl J Med. 2016;374(16):1533-42.

10. Sacco RL, et al. An updated definition of stroke for the 21st century: a statement for healthcare professionals from the American Heart Association/American Stroke Association. Stroke. 2013:44(7):2064-89.

11. Lovett JK, Coull AJ, Rothwell PM. Early risk of recurrence by subtype of ischemic stroke in population-based incidence studies. Neurology. 2004; 62(4):569-73.

12. Adams HP Jr, et al. Classification of subtype of acute ischemic stroke. Definitions for use in a multicenter clinical trial. TOAST. Trial of org 10172 in acute stroke treatment. Stroke. 1993;24(1):35-41.

13. Leoo T, et al. Risk factors and treatment at recurrent stroke onset: results from the recurrent stroke quality and epidemiology (RESQUE) study. Cerebrovasc Dis. 2008;25(3):254-60.

14. Petty, G.W., et al., Ischemic stroke subtypes: a population-based study of functional outcome, survival, and recurrence. Stroke, 2000. 31(5): p. 10621068.

15. Murat Sumer M, Erturk O. Ischemic stroke subtypes: risk factors, functional outcome and recurrence. Neurol Sci. 2002;22(6):449-54.

16. Gorelick PB, et al. Large artery intracranial occlusive disease: a large worldwide burden but a relatively neglected frontier. Stroke. 2008;39(8): 2396-9.

17. Ois $A$, et al. Factors associated with a high risk of recurrence in patients with transient ischemic attack or minor stroke. Stroke. 2008:39(6):1717-21.

18. Hankey GJ, et al. Long-term risk of first recurrent stroke in the Perth community stroke study. Stroke. 1998;29(12):2491-500.

19. Dietrich WD, et al. Thromboembolic events predispose the brain to widespread cerebral infarction after delayed transient global ischemia in rats. Stroke. 1999;30(4):855-61 discussion 862.

20. Danton $\mathrm{GH}$, et al. Temporal profile of enhanced vulnerability of the postthrombotic brain to secondary embolic events. Stroke. 2002;33(4): 1113-9.

21. Fuster V. Epidemic of cardiovascular disease and stroke: the three main challenges. Presented at the 71st scientific sessions of the American Heart Association. Dallas, Texas. Circulation. 1999:99(9):1132-7.

22. Rashid P, Leonardi-Bee J, Bath P. Blood pressure reduction and secondary prevention of stroke and other vascular events: a systematic review. Stroke. 2003;34(11):2741-8.

23. Lawes CM, et al. Blood pressure and stroke: an overview of published reviews. Stroke. 2004;35(4):1024. 
24. Turnbull F. Effects of different blood-pressure-lowering regimens on major cardiovascular events: results of prospectively-designed overviews of randomised trials. Lancet. 2003;362(9395):1527-35.

25. Xu G, et al. Recurrence after ischemic stroke in Chinese patients: impact of uncontrolled modifiable risk factors. Cerebrovasc Dis. 2007;23(2-3):117-20.

26. Laloux P, Lemonnier F, Jamart J. Risk factors and treatment of stroke at the time of recurrence. Acta Neurol Belg. 2010;110(4):299-302.

27. Bamford J, et al. Classification and natural history of clinically identifiable subtypes of cerebral infarction. Lancet. 1991;337(8756):1521-6.

28. Toni $D$, et al. Types of stroke recurrence in patients with ischemic stroke: a substudy from the PRoFESS trial. Int J Stroke. 2014;9(7):873-8.

\section{Publisher's Note}

Springer Nature remains neutral with regard to jurisdictional claims in published maps and institutional affiliations.

\section{Submit your manuscript to a SpringerOpen ${ }^{\circ}$ journal and benefit from:}

- Convenient online submission

- Rigorous peer review

- Open access: articles freely available online

High visibility within the field

- Retaining the copyright to your article

Submit your next manuscript at $\boldsymbol{\nabla}$ springeropen.com 